\title{
La Hispania del Nuevo Mundo. Historia indiana y dinámicas políticas en el reinado de Felipe III*/
}

\author{
Hispania of the New World. Colonial American History \\ and Political Dynamics in the Reign of Philip III
}

\author{
Amorina Villarreal Brasca \\ ORCID iD: http://orcid.org/0000-0002-1997-8039 \\ Universidad Complutense de Madrid
}

En el reinado de Felipe III el ámbito de representaciones textuales indianas conoció un tiempo de análisis renovados que alimentaron las discusiones y las prácticas políticas de implicaciones americanas. En el presente artículo se analiza cómo la construcción de la historia de América participó activamente en los ámbitos discursivos de comienzos del siglo XVII como arma política.

Palabras clave: Consejo de Indias; Historia Política Indiana; Felipe III; Pedro de Valencia; José de Acosta; Monarquía Hispánica; Siglo XVII.

In Philip III's reign, the field of textual representation from the Indies entered a period of renewed analysis that fueled discussions and political practices of implications of the Americas. This paper analyzes how the construction of the Indies' past was actively involved in the discursive fields of the early seventeenth century as a political weapon.

Keywords: Council of the Indies; Political History of the Indies; Philip III of Spain; Pedro de Valencia; José de Acosta; Spanish Monarchy; 17th century.

Copyright: (C) 2018 CSIC. Este es un artículo de acceso abierto distribuido bajo los términos de la licencia de uso y distribución Creative Commons Reconocimiento 4.0 Internacional (CC BY 4.0).

* El presente estudio se ha realizado en el marco del Proyecto de Investigación de I+D «Entre venalidad y corrupción en la Monarquía Hispánica durante el Antiguo Régimen» (HAR2014-55305-P), financiado por el Ministerio de Economía y Competitividad de España. También ha sido posible gracias a una beca predoctoral de la Universidad Complutense de Madrid. Del mismo modo, agradezco a Jacobo Storch de Gracia y Asensio sus generosas aportaciones y consejos para la comprensión del mundo clásico. 


\section{Un espacio de representaciones textuales de Indias}

El reinado de Felipe III conoció el surgimiento de textos fundamentales para el acervo de la cultura política indiana. Los escritos con los que se cuenta para el estudio de este período, tanto impresos como manuscritos, permiten múltiples acercamientos que sirven de guía hacia los debates sobre las Indias en los inicios del siglo XVII. Al igual que sucedió con otros reinos, las alusiones a América comprendieron mucho más que aquello ocurrido exclusivamente a sus habitantes o en sus territorios. De hecho, la vastedad de las implicaciones de las dinámicas indianas, con repercusiones en la política, economía, sociedad y cultura del conjunto de la monarquía hispánica (y aun más allá), resulta clave para comprender la profusión y diversidad de escritos que versaron sobre las problemáticas del Nuevo Mundo. ${ }^{1}$

Cuando el historiador se sumerge en busca del pulso político de la época, poco a poco comienza a desarrollar la presunción de que, más allá de la heterogeneidad, las «raíces, rasgos e influencias» ${ }^{2}$ de esta pluralidad generaron un paraje imaginario en el que coincidieron, y en algunos casos dialogaron, las más variadas formas textuales. ${ }^{3}$ En este sentido, se podría hablar de la existencia de un ámbito de representaciones indianas en forma de textos escritos, entendido como un espacio en el que convergieron informaciones, reflexiones, inferencias, propuestas y debates respecto de las cuestiones americanas.

Este ámbito, al igual que otros espacios de discusión de la monarquía, se valió para su comunicación de un lenguaje común que compartieron los reinos, como verdadero conjunto de signos de expresión para ser comprendido. Las características integradoras de este lenguaje no le hicieron, sin embargo, indiscutible. El lenguaje de la monarquía no fue estático, porque las representaciones que lo alimentaron constituyeron entidades vivas, con capacidad para construir, y destruir, experiencias políticas y sociales. Por ello el valor de las representaciones textuales, en tanto que generadoras de sentido, viene dado por su capacidad para ofrecer diferentes claves con las que comprender cuáles fueron los temas, las ideas y los debates sobre las

1 Sigue siendo imprescindible Elliott, 1972. Véase también Latasa, 2011; y las obras sobre la llamada escritura imperial: Pizarro, 1993; González Ortega, 2006.

2 Valladares, 2013, 60.

3 Tomando la propuesta de Chartier de los textos como representaciones. Chartier, 1992, y 2007,12 
Indias, pero también los gestos y comportamientos políticos. Las representaciones nos ofrecen, de esta manera, discursos y prácticas de las polifónicas relaciones políticas indianas.

Historiar, teorizar, informar, peticionar y proponer, elevar y entretener, fueron posiblemente los principales ejercicios de los que discurrieron sobre las Indias en este tiempo, ya sea de manera exclusiva o puntual, en un texto, y a sabiendas, la mayoría de ellos, del eventual potencial de sus contribuciones. Aun con matices y divergencias, los asiduos intercambios de unos a otros escritos ponen de relieve la fuerza comunicadora de ese espacio de convergencia. Y aunque fueron muy variados los temas que se sometieron a estas acciones, en este estudio nos interesa la vertiente política, es decir, los nodos centrales del debate americano en el reinado de Felipe III. ¿Por qué interesa este período? Porque desde finales del reinado de Felipe II y principalmente durante el de su sucesor surgieron textos que dieron vitalidad a las cuestiones indianas, dando a conocer cuáles fueron los debates y mostrando cómo se renovaron las respuestas dadas a sus problemáticas. Pero hay más, asumiendo que estos textos constituyeron representaciones, es pertinente considerar que fueron actores de las relaciones políticas, con capacidad para crear discursos pero también para movilizar prácticas, en un tiempo donde la palabra escrita fue un camino altamente transitado y en el que los vínculos entre los escritos y los escritores demuestra la consolidación de una comunidad política indiana.

Aunque en esta ocasión no se entrarán a considerar a fondo los textos de mayor pureza teórica, sin embargo, parece oportuno señalar que en el reinado de Felipe III iniciaron su andadura una serie significativa de ellos. Más allá de lo relacionado con su circulación o impresión, sin duda relevante, se quiere hacer constar la confluencia, en ese espacio de representaciones textuales indianas cargado de préstamos, del comienzo de las actividades de intelectuales cuyos nombres van profundamente asociados al pensamiento político americano. Se trató de textos que adquirieron la calidad de referentes y fueron generados por Juan de Zapata y Sandoval, ${ }^{4}$ Juan Ortiz de Cervantes, ${ }^{5}$ o Juan de Solórzano Pereira, ${ }^{6}$ entre los más destacados. Verdaderos constructores políticos, con recíprocos y sucesivos préstamos

4 Zapata y Sandoval, 2004 [1609].

5 Ortiz de Cervantes, 1968 [1619] y 1620.

6 El jurista comenzó a escribir siendo oidor de la Audiencia de Lima. Carta del oidor Juan de Solórzano Pereira al Consejo de Indias, Guancavelica, 8 de abril de 1618, Archivo General de Indias (AGI), Audiencia de Lima, 149, s/f. 
de argumentos ajenos, que compusieron nuevos fragmentos en las relaciones de poder con las Indias, y que serán retomados por un nutrido número de teóricos de diversas disciplinas durante toda la andadura de la monarquía en América.

En este tiempo se utilizaron palabras escritas para representar las principales preocupaciones indianas, y estas no solo fueron abordadas en escritos políticos y jurídicos. Antes bien, podría decirse que la inclinación por la historia fue una de las tendencias preferidas para representar las inquietudes del Nuevo Mundo. Ya sea de forma íntegra o como parte de un texto, las representaciones del mundo indiano encontraron refugio, e impulso, en los brazos de la nodriza de los hombres. En este sentido, el principal objetivo de este artículo no es hacer un trabajo de literatura indiana o del Siglo de Oro, ${ }^{7}$ sino poner de manifiesto la vertiente política de la historia de los reinos de Indias durante el reinado de Felipe III.

\section{Historiar las Indias}

El profundo valor de las representaciones textuales indianas de corte histórico fue evidente para una destacada tradición historiográfica que se ocupó de la edición y estudio de obras fundamentales, sabedores — como señaló Carlos Gálvez- de su naturaleza como productos culturales que permiten la comprensión y asociación a distintos fenómenos del pasado. ${ }^{8} \mathrm{El}$ importante conjunto de relaciones y crónicas escritas durante el siglo XVI constituyó una abundante fuente de informaciones y de sensibilidades que las siguientes generaciones utilizaron e interpretaron. El recurrente aprovechamiento de los textos anteriores tuvo mucho de ejercicio de usufructo, con todas las ventajas de una práctica que logró la conservación del patrimonio de representaciones existente a la vez que permitió su actualización. Estas re-elaboraciones sucedieron sobre las obras de mayor impacto dentro de los circuitos de la monarquía pero también de escritos silenciados, bien por el secretismo de la Corona respecto de las informaciones indianas o por la imposibilidad que tuvieron otras de sortear la censura previa. ${ }^{9}$

7 A pesar del enorme valor y utilidad de estos trabajos, desde los más clásicos hasta los más recientes, resulta imposible citar a todos. Además, esto no es un artículo acerca del estado de la cuestión de los estudios sobre los textos utilizados.

8 Gálvez Peña, 1998, IX.

9 Bouza, 2008, 30-31. Véase también De los Reyes, 2000, especialmente capítulos V y VI; Friede, 1959; y los trabajos del grupo «Escrituras Silenciadas», http://escrituras-silenciadas.com. 
Pasados los tiempos iniciales, en principio caracterizados por escritos de mayor carga informativa y descriptiva, la siguiente promoción encontró en el relato histórico una forma narrativa con la que acometer la construcción teórica del pasado indiano y también una serie de ejercicios de reflexión crítica sobre su presente. ${ }^{10}$ Para ponderar el interés de fijar el estudio en el reinado de Felipe III, deben subrayarse algunos de los textos (que no todos) de alto contenido histórico que se escribieron en este tiempo y que configuraron un referente para los contemporáneos y para la cultura política indiana a partir de ese momento. Se trató de Crónica mexicana (1598) y Crónica Mexicáyotl (1609), de Hernando de Alvarado Tezozomoc, nieto del emperador Moctezuma; Sátira hecha a las cosas que pasan en el Pirú (1598), escrita por el mordaz Mateo Rosas de Oquendo; El peregrino indiano (1599), épica panegírica del hombre de letras Saavedra Guzmán; Las relaciones universales del mundo (1599) y Descripción de todas las Provincias, Reynos, Estados y Ciudades principales del mundo (1602), que reunió Giovanni Botero y en las que polemizó con las descripciones clásicas de las Indias; Historia General, o Décadas (1601-1615), discurso autorizado del cronista de Indias Antonio de Herrera y Tordesillas; Grandeza mexicana (1604), por el erudito Bernardo de Balbuena; Sumaria relación de las cosas de la Nueva España (1604), del benemérito Baltasar Dorantes de Carranza; La relación de las antigüedades del Reyno del Pirú (1608), que defendió el noble indígena Pachacuti Yamqui; Conquista de las islas Malucas (1609), del egregio Bartolomé Leonardo de Argensola; Comentarios Reales de los Incas (1609), escritos por el mestizo y honorable Inca Garcilaso de la Vega; Historia de Nuevo México (1610), del criollo formado en Salamanca don Gaspar de Villagrá; Historia General del Perú (1611), por el influyente fray Martín de Murúa; Nueva crónica y buen gobierno (1615), relato descarnado de Felipe Guaman Poma de Ayala; Monarquía Indiana (1615), defensa histórica y política de las Indias del fraile Juan de Torquemada; Noticia General del Perú (1613-1635), texto clave del contador Francisco López de Caravantes y contemporáneo de la Corónica Moralizada (1615-1638), del fraile Calancha; Descripción de Indias (¿1616?), uno de los textos indianos finalizados por el humanista Pedro de Valencia; y Memorial de las Historias del Nuevo Mundo (1631), concebida durante el reinado de Felipe III por fray Buenaventura de Salinas, quien ante tanta producción histórica (y también jurídico-teórica) decidió construir un relato aglutinador.

10 Lohmann Villena calificó este período como una «convergencia de talentos» en el que se generó un verdadero «movimiento intelectual» para el caso del Perú. Lohmann, 1985, XIII y XIX. 
El final del siglo XVI conoció un mayor espíritu crítico en los textos de Indias. Posiblemente, quien mejor representó este movimiento fue José de Acosta y su Historia Natural y Moral de las Indias (1590). El jesuita contó con la experiencia de una larga trayectoria en territorios tanto del Perú como de la Nueva España, y tras haber leído y consultado diversos libros y relaciones de lo sucedido en las Indias, sostuvo que «hasta ahora no he visto autor que trate de declarar las causas y razón de tales novedades y extrañezas de naturaleza, ni que haga discurso e inquisición». ${ }^{11} \mathrm{La}$ carencia que subrayó Acosta fue la que intentó suplir con su obra, porque aunque el mismo autor sostuvo que el Nuevo Mundo ya no era nuevo y se había escrito mucho sobre él, sí que «en alguna manera se podrá tener esta Historia por nueva», ${ }^{12}$ no por los temas o los datos de la obra, sino por la novedad del método. El estudio del jesuita, cargado de nuevas propuestas de interpretación acerca de América, tuvo buena acogida en la corte y recibió aprobación por parte de los censores y licencia de Felipe II para su impresión. Además, el monarca le extendió permiso para una dedicatoria a su hija mayor, Isabel Clara Eugenia, a quien el autor encomendó su obra con el propósito de que la infanta tuviera ocasión de «considerar en obras que el Altísimo ha fabricado en la máquina de este mundo, especialmente en aquellas partes que llamamos Indias, que por ser nuevas tierras, dan más que considerar, y por ser de nuevos vasallos que el sumo Dios dio a la Corona de España, no es del todo ajeno ni extraño su conocimiento». ${ }^{13}$ De este modo, Acosta colocó la historia de los reinos de Indias en el corazón de la corte y en las manos de la posible soberana de América.

Respecto de la percepción del jesuita sobre una cierta deficiencia de los escritos históricos, cabe apuntar que esta se corresponde con un momento historiográfico concreto. Como apuntó Gil Pujol, el Renacimiento había dado auge y señas de identidad al trabajo histórico, guiado por la lux veritas de Cicerón y en búsqueda constante de esa verdad que Tucídides había consagrado como posible de hallar. Para finales del siglo XVI, la historia se hallaría en un «punto muerto», y de aquellas anteriores conciliaciones exitosas al realizar la escritura del pasado sin faltar a la verdad para utilidad pública, se había pasado «a una extensa acumulación de información, carente del nervio analítico que había elevado a la mejor historia humanista». ${ }^{14}$ Para

11 Acosta, 2002 [1590], 57.

12 Ibidem.

13 Ibidem, 53.

14 Gil Pujol, 1991, XXIV. 
esta situación de estancamiento, la influencia de los comentarios de Justo Lipsio a los clásicos Tácito y Séneca significó un importante estímulo en la recuperación del interés por la historia. ${ }^{15} \mathrm{El}$ constructor de la teoría de la razón de Estado impulsó el movimiento historiográfico. Tal como escribió Lipsio, a los príncipes no podían faltarles «buenos ingenios, que escriban las crónicas de su tiempo», ${ }^{16}$ y a ello añadió Giovanni Botero que tampoco los príncipes podían dejar de patrocinar «una historia bien escrita que sea leída por todo el mundo y recorra el mundo entero». ${ }^{17}$ Es así como desde inicios del siglo XVII se reanudó con interés el ejercicio de hacer historia, continuando una tradición renacentista a la vez que incorporando, en mayor o menor medida, una visión más crítica y documentada del pasado. La vigorización de este período no solo alcanzó a los monarcas y sus círculos más cercanos, también los súbditos, las ciudades y otras instituciones florecieron en narraciones por encargo o voluntarias. En este sentido, las Indias fueron parte de este interés general por la historia. Así y todo, avanzado el reinado de Felipe II se puede hablar de una tendencia específica cuando se agudizó la preocupación por la historia de América y se tomaron medidas concretas, como la creación de una figura ad hoc: la del cronista de Indias. ${ }^{18}$ Después de todo, fue cuestión de consolidar la noción de Imperium, concepto político fundamental para apuntalar la configuración territorial de la Monarquía.

\section{El Consejo de Indias y la Historia de América}

El importante impulso que recibió la figura del cronista de Indias durante el reinado de Felipe III fue de la mano de uno de los presidentes más sobresalientes que tuvo el Consejo de Indias, el VII conde de Lemos. ${ }^{19}$ Una vez presentados, el joven presidente convenció a Pedro de Valencia para que permaneciera en la corte, donde tan estimados serían sus consejos. ${ }^{20}$ A la vez, el conde de Lemos le ofreció el oficio de cronista de Indias, como forma de asegurar una posición en la corte y con el objetivo de que este

15 Kagan, 2010, 181-183.

16 Lipsio, Los seys libros de las politicas, citado en Kagan, 2010, 182.

17 Botero, Della ragion di Stato, citado en Kagan, 2010, 182.

18 García Hernán, 2006. Cuesta, 2007.

19 Pedro Fernández de Castro y Andrade fue presidente del Consejo de Indias entre los años 1603 y 1609. Sobre su presidencia, véase Enciso, 2008; Villarreal, 2016.

20 Informaciones sobre el cronista Pedro de Valencia, s/l, s/d, AGI, Indiferente General, 752, s/f. Paniagua, 1996. 
realizara un trabajo que fuera verdaderamente analítico con el pasado pero proyectado hacia el presente de las Indias. Tal como reza el título de su nombramiento, fue designado historiógrafo y cronista general de las Indias Occidentales,

teniendo consideración de las muchas letras, erudición, lectura, inteligencia de lenguas, continuo estudio y curiosidad en inquirir y saber la escritura sagrada, doctores y historiadores y otras muchas y buenas partes que concurren en vos [...] y considerando lo mucho que importa que semejantes personas se ocupen en hacer las Historias por el crédito, autoridad y verdad con que su escritura se a de conservar en la memoria de las gentes. ${ }^{21}$

Valencia aceptó con la condición de que el oficio de cronista no fuera una carga para sus estudios, para los que pidió garantías de libertad, «no porque no sea el oficio de cronista muy honroso y digno de que lo sirvan personas muy calificadas: sino porque el ejercicio de él requiere no solo letras y estudios, sino noticia y experiencia» y porque en algunas ocasiones esta actividad podía suponer la censura de algunas vidas y comportamientos, un trance en el que Valencia no quiso verse sometido ni entrar a valorar bajo ningún «interés humano». ${ }^{22}$ Esto último puede que fuera una alusión a la reputación que siempre acompañó la actividad del otro cronista indiano, Antonio de Herrera y Tordesillas, quien fue acusado en más de una ocasión de poner precio a la consideración de los personajes de sus escritos. ${ }^{23}$

Más allá de la interesante convivencia de dos cronistas indianos con actitudes opuestas respecto de la tarea del historiador - lo cual demuestra las muchas maneras de representar el pasado aun en los discursos autorizados-, aquí interesa resaltar cómo la tendencia por una historia escrita por los más prominentes intelectuales alcanzó el centro de poder de las Indias en la corte e intentó desplazar los otros modos. El conde de Lemos introdujo más iniciativas de mecenazgo relacionadas con la escritura de la historia y el gobierno de las Indias. ${ }^{24}$ Entre ellos cabe recordar el encargo

21 Copia del Título de Historiographo y Chronista General de las Indias Occidentales para el licenciado Pedro de Valencia, Madrid, 4 de mayo de 1607, AGI, Indiferente General, 874, s/f.

22 Memorial de Pedro de Valencia, cronista, s/1, s/d, AGI, Indiferente General, 752, s/f.

23 Paniagua, 1996. Kagan, 2010, 243-282.

24 Es más, el ya mencionado Juan de Zapata declaró el papel protagónico del conde en su texto sobre la justicia distributiva y la oposición a la acepción de personas en los reinos indianos. Zapata y Sandoval, 2004 [1609], 52-54. También Juan de Solórzano dejó constancia de que fue Lemos quien propició su andadura en el Perú, para que los mejores egresados de la Universidad de Salamanca adquirieran experiencia y se encargasen del gobierno práctico y teórico de Indias. Carta del Dr. Juan de Solórzano Pereira al fiscal del Consejo de Indias, Lima, 1 de mayo de 1620, AGI, Audiencia de Lima, 96, s/f. 
a Bartolomé Leonardo de Argensola para hacer una historia documentada de la conquista de las islas Molucas - en cuya empresa fue vital la participación novohispana- y reafirmar la legitimidad de Felipe III en unos territorios disputados por otros reinos europeos..$^{25}$

Las consultas del Consejo de Indias durante su presidencia dan buena cuenta de la búsqueda de una construcción fidedigna a la par que, conforme a los paradigmas de la razón de Estado, una historia indiana en equilibrio, que se abriera paso, guiada por el documento, hacia una verdad objetiva que robusteciera los credos políticos de la monarquía. Así lo entendió Valencia cuando afirmó:

Y porque yo deseo cumplir con las obligaciones de mi oficio y en todas maneras servir y agradar a V.A. y conforme al dicho oficio a la misma razón del oficio de coronista, es necesario que yo escriba argumento de historia señalado por V.A. y que las cosas no sean colegidas de libros impresos solamente, ni de fama y relaciones vulgares, sino sacadas de descripciones, relaciones y papeles auténticos. ${ }^{26}$

Sin embargo, no fue fácil hacer coincidir en un texto los equilibrios entre verdad, método y razón de Estado. De facto, Pedro de Valencia fue encargado de escribir una historia de Chile, a propósito de la guerra del Arauco, y aunque comenzó la tarea (que fue aprovechada posteriormente por Luis Tribaldos de Toledo), el humanista desistió del intento y acabó por declararse incapaz de concluir la empresa. Valencia conoció a través de los documentos del Consejo de Indias la violenta trayectoria del proceso de conquista y conservación del reino de Chile, y encontró imposible hacer brillar la verdad por encima de las reprobables conductas de algunos vasallos y la inoperancia que en ciertas ocasiones demostró la Corona. El Consejo supo de la cuestión a través de un billete del duque de Lerma - cuya intercesión pone de manifiesto la constante influencia del valido en los asuntos del órgano consultivo--, en el que se expusieron las dificultades del trabajo del cronista, ${ }^{27}$ de quien se dijo que «habiéndolo hecho y querido escribir sobre ello [la guerra de Chile] era de parecer que no convenía dar

25 Leonardo de Argensola, 2009 [1609].

26 Petición de Pedro de Valencia, cronista general de Indias, s/1, 18 de marzo de 1609, AGI, Indiferente General, 1432, s/f.

27 Billete del duque de Lerma en la pretensión de Pedro de Valencia, cronista, Palacio, 16 de julio de 1616, AGI, Indiferente General, 752, s/f. El proceso sobre la negativa de Pedro de Valencia comienza con un billete de Lerma al Consejo de Indias, lo cual implica que el cronista acudió al valido para solventar su situación. 
más noticia de aquella guerra de lo que está escrito de ella». ${ }^{28}$ Haciendo gala de su pragmatismo, el Consejo propuso al rey que no se tuvieran en cuenta los argumentos del cronista y se le reclamara un trabajo escrito, del modo que fuera. Por el contrario, el monarca, a través de su privado, ordenó que se aceptara la decisión de Valencia y que se le dejara continuar con otros textos que el humanista sí consideró aceptos al servicio de la verdad y del monarca.

Resulta importante subrayar las razones por las cuales Pedro de Valencia creyó que no se debía ahondar más en el pasado chileno, y ello fue porque entendió que «haciendo en ella el deber del oficio de historiador, se han de ofender personas de calidad, y sus hijos y familias, y se ha de infamar la nación española de injusticias, avaricias, y crueldades, que gustarían mucho de saber los extranjeros, herejes y enemigos de esta monarquía». ${ }^{29}$ Desde luego, el ejercicio de una historia fiel a las fuentes no podía atentar contra la reputación de la monarquía, uno de los principios rectores de la política moderna, ni convertirse en herramienta para aquellos que socavaron y negaron la autoridad del monarca. Más interesante aun puede ser la idea de que la pureza en el oficio de historiador pudo traer graves consecuencias para la consideración de los súbditos que tuvieron sus méritos en los reinos de Indias, negándose Valencia a ejercer de «pregonero de culpas ajenas». ${ }^{30}$

Los miembros del Consejo de Indias fueron conscientes del impacto de los contenidos que se representaron en los textos históricos, y así lo manifestaron a propósito de una consulta solicitando provisión real para recoger todos los impresos de La Dragontea, por sus informaciones inexactas sobre América. Para el Consejo, el poema épico de Lope de Vega «contiene muchas cosas de Indias contra la razón cierta que se tiene dellas y en perjuicio de muchos que han servido bien». ${ }^{31}$ En este sentido, el sínodo señaló la necesidad de una historia puntual y apegada a la verdad de los hechos pasados, especialmente porque de ellos se valieron los vasallos para «fundar las pretensiones de que se les gratifiquen sus servicios, o de

28 Consulta del Consejo de Indias en la pretensión de Pedro de Valencia, cronista, Madrid, 17 de septiembre de 1616, AGI, Indiferente General, 752, s/f.

29 Memorial de Pedro de Valencia, cronista, s/l, s/d, AGI, Indiferente General, 752, s/f.

30 Ibidem. Pedro de Valencia tuvo una estrecha relación con Fernando Machado, quien fue a servir a Indias como relator de la Audiencia de Quito y prosperó hasta alcanzar la plaza de oidor en la Audiencia de Chile, donde fue de ayuda para la tarea del humanista. Véase Morocho, 1993.

31 Consulta del Consejo de Indias por La Dragontea, Madrid, 13 de marzo de 1599, AGI, Indiferente General, 745, s/f. 
sus pasados, y poner pleitos y demandas». ${ }^{32}$ Es más, el Consejo apuntó que esta fue una de las principales razones de la creación de la figura del cronista específico para Indias y defendió su jurisdicción en las decisiones relacionadas con estos escritos, porque, en definitiva, fue en este tribunal donde acabaron dichas causas. Por ello pidió al rey que «para evitar los inconvenientes referidos y relaciones encontradas como se ha visto, que V. M. ordene al Consejo de Castilla que no de licencia para que se pueda imprimir ningún libro en que se trate de cosas de Indias sin que primero se vea en el consejo dellas, donde es fuerza que se a de tener mas particular y puntual relación que en otro Tribunal». De esta manera puso de manifiesto su celo con los textos relacionados total o parcialmente con la historia de América, al igual que para con la actividad del Consejo de Castilla en los asuntos indianos, por las repercusiones directas en sus labores de gobierno y por su íntima relación con el papel político del monarca en los reinos de Indias, como principal responsable y garante de la administración de la gracia. En este sentido, se puede decir que el Consejo de Indias intentó encausar la coincidencia entre el interés de la Corona por la historia de sus reinos junto al servicio del vasallo en forma de ensayo histórico, a la vez que intentó evitar repercusiones en la administración política de la gracia real hacia los méritos americanos. ${ }^{33}$

\section{Historia como servicio}

A pesar de los esfuerzos institucionales, la historia que avaló el Consejo representó solo una parte de los textos indianos de contenido histórico. Conociendo la disposición de la monarquía hacia la historia, y teniendo en cuenta la lógica del servicio al rey como uno de los umbrales interpretativos de los comportamientos sociales de la Edad Moderna, se puede decir que los súbditos encontraron en la escritura de la historia una forma de servicio para entregar al monarca, al virrey u otras autoridades. En este sentido, se detecta en el corpus de obras que el servicio fue la recurrente intención de la escritura. Ahora bien, fueron varias las maneras de afrontar la práctica de este servicio.

En un primer nivel, los servidores ejercieron de historiadores a la espera de la justa recompensa por el esfuerzo realizado. Sin embargo, la

32 Ibidem.

33 Respecto al principio del servicio al rey, véase Esteban, 2012. 
mayoría de ellos agregaron a este más pretensiones o causas, valiéndose del relato histórico para construir discursos con grados diferentes de reivindicación. Y no solo a propósito de los premios reclamados por los servicios de los beneméritos de la tierra, una motivación común en los indianos, sino que los casos y las causas mostraron una complejidad mayor.

Por ejemplo, en El peregrino indiano se declaró la oportunidad del servicio a Felipe III por ese reino al que se calificó de carente de historia, pues según el autor lo que le animó aun más en la empresa fue el saberse descendiente de conquistadores y nacido en México, «donde ningún historiador ha avido». ${ }^{34}$ Con esta premisa, desarrolló un relato épico en el que se describieron los hechos del pasado pero también las justas causas del presente. Saavedra Guzmán expuso, de forma imbricada con la crónica, su causa personal como ex-corregidor destituido del cargo por falsas acusaciones de sus opositores políticos. De esta manera, en un ejercicio acumulativo, hizo constar el pasado, pero también sus problemas con el ejercicio del poder a nivel local y la dificultad del acceso a la justicia real desde las Indias. Esto es, a la par que hizo historia de los mexicas y los hechos heroicos de sus antepasados, fue reflexionando sobre el presente indiano y reclamando la imparcialidad que merecieron los actos de siglos anteriores tanto como los puntuales de su propia carrera de servicio. ${ }^{35}$

En la rica diversidad del servicio de hacer historia, otros textos llegaron a justificar la escritura de planteamientos políticamente controvertidos en los presupuestos del acto de servir, como si ello les hubiese otorgado un escudo protector que permitió dar contenidos críticos a los relatos.

Así, en la obra del Inca Garcilaso se comenzó por declarar la voluntad de contribuir a la edificación de la historia de las Indias, sin deseos de contradecir a nadie, únicamente por el interés de «servir a la república cristiana» $\mathrm{y}$ «forzado del amor natural de la patria». ${ }^{36}$ Además, y en consonancia con el renovado interés por una historia documentada, se señaló que no solo se había sido oyente y testigo del gobierno de los reyes incas, sino que también «consta claro, no solamente por las cuentas y nudos anales de los indios, mas también por los cuadernos fidedignos, escritos de mano, que el virrey Francisco de Toledo mandó a sus visitadores y jueces y a sus escribanos que escribiesen, habiéndose informado largamente de los indios

34 Saavedra, 2008 [1599], 215.

35 Ibidem, 217-218.

36 Garcilaso de la Vega, 1995 [1609], 4. 
de cada provincia. Los cuales papeles están hoy en los archivos públicos».37 Una vez asentados los principios de la autoridad de las fuentes, la obra edificó un relato del pasado prehispánico del reino del Perú a través de la exposición de hechos históricos a los que se realizó una lectura presentista, comparando de forma constante la antigua realidad incaica con la cultura política de la monarquía hispánica. La narración buscó poner de manifiesto la naturaleza real del pueblo incaico, elevado al estatus de «monarquía» (un ejercicio común a muchas de las representaciones históricas de este período), a sabiendas de que esta categoría significó implícitamente que los monarcas españoles estuvieron llamados a respetar esta condición para con el reino y en consecuencia para con sus naturales. Establecido este principio político, el ejercicio de la historia le permitió al Inca Garcilaso introducir el elemento testimonial, es decir, su relato como hijo de un benemérito y una princesa inca pero huérfano de gracia real, añadiendo a las disquisiciones teóricas sobre la monarquía peruana el componente fáctico de su caso. Eso sí, a pesar del tono conciliador que recorre la obra —y que reveló un anhelo de reparación-, en más de una ocasión el texto subrayó con dureza la justicia de las reclamaciones del autor y de los vasallos del rey en Indias. Y no solo denunció las sinrazones de acuerdo a la calidad teórica de los reinos americanos, sino que también mentó las fuerzas de sus riquezas como argumento dialéctico.

Ciertamente a propósito de la historia, el texto de Garcilaso puso en valor la oralidad de los relatos andinos del pasado, aun teniendo conciencia de que su legitimidad sería cuestionada. Resulta interesante cómo se utilizó, frente a una posible crítica respecto de estas fuentes, un considerando que tuvo menos que ver con las consecuencias jurídicas de ver al Perú como un reino que fue monarquía. Por el contrario, se pasó a un ámbito más terrenal, donde cobraron fuerza probatoria los hechos, y ese lugar, común a tantos textos, fue la consideración de que las Indias tuvieron importancia para la monarquía en razón y medida de la contribución de sus riquezas. Este pensamiento fue un tema nuclear en el debate político, donde la historia tuvo un papel significativo en las interpretaciones que se fueron formulando sobre la riqueza de América. ${ }^{38}$

Para el texto del Inca Garcilaso, frente a la vital aportación del Perú, teniendo en cuenta lo que significó el patrimonio de este reino para el

37 Ibidem, 277.

38 Cárceles de Gea, 2005. 
esplendor del conjunto de la monarquía, no pudo caber para con su pasado otra actitud que la aceptación y la admiración,

porque aunque algunas cosas de las dichas (y de las que se dirán) parezcan fabulosas, me pareció no dejar de escribirlas [...] Porque, en fin, de estos principios fabulosos procedieron las grandezas que en realidad, de verdad, posee hoy España. Por lo cual, se me permitirá decir lo que conviniere, para la mejor noticia que se pueda dar de los principios, medios y fines de aquella monarquía. ${ }^{39}$

La contundencia de estas declaraciones seguramente estuvieron dirigidas a contrarrestar la circulación de un argumento específico sobre el pasado indiano visto como una mera alegoría, y que fue sostenido, entre otros, por Sebastián de Covarrubias, quien en su Tesoro de la Lengua Castellana opinó en la voz Fábula: «Los que habéis leído las crónicas de las Indias, cosa que pasó ayer, tan cierta y tan sabida, mirad cuántas cosas hay en su descubrimiento y en su conquista que exceden a cuanto han imaginado las plumas de los vanos mentirosos que han escrito libros de caballerías, pues éstas vendrá tiempo que las llamen fábulas». ${ }^{40}$

Más virulento fue el lenguaje de las imágenes y las palabras del texto tradicionalmente atribuido a Felipe Guaman Poma de Ayala, ${ }^{41}$ una vez más escudado en el servicio, en este caso al reino, que no al rey. El texto se dirigió a Felipe III para cimentar los presupuestos de su representación del pasado al igual que del presente político del Perú: «Sacra Católica Real Magestad, vuelvo como príncipe de los indios de este reino. Vuelvo por el reino». ${ }^{42}$ Pero la licitud de su discurso histórico parece que estuvo dada más por su condición de verdadero cronista de la monarquía incaica, además de la calidad de su testimonio como príncipe de la casa real peruana: «y así es muy justo que yo de testimonio y firmado de mi nombre como coronista y príncipe de este reino». El propósito de hacer una historia cierta, documentada y al servicio del reino buscó algo más que conformar un espacio de evocación del glorioso pasado incaico, porque «así escribo esta historia para que sea memoria, y que se ponga en el archivo para ver la justicia». ${ }^{43}$

39 Ibidem, 50.

40 Covarrubias, 2006 [1611], 394. Es de señalar que Pedro de Valencia fue quien otorgó la censura de dicha obra, firmada el 3 de mayo de 1610 «por ser conveniente que de la propiedad, pureza y elegancia de una lengua se escriba en el tiempo que ella más florece» (Ibidem, IIr). Véase al respecto De los Reyes, 2000, 329.

41 Guaman Poma, 1987 [1615]. Respecto del debate sobre la autoría véase Numhauser, 2007.

42 Guaman Poma, 1987 [1615], 1068.

43 Ibidem, 1070. 
Es decir, el ulterior propósito de la representación del imperio peruano, de la conquista española y la posterior administración del territorio hasta el siglo XVII, fue escrita para ser conservada ${ }^{44}$ con la intención de que pudiera convertirse en herramienta para estimular el principal mecanismo político que vinculó los vasallos indianos con el titular de sus reinos: la justicia real. Las diferentes denuncias y demandas, del mismo modo que las propuestas y las alabanzas vertidas en las páginas de la Nueva Crónica, se expusieron también como principios activos con los que inducir la reacción en cadena de la administración de la gracia. No solo para el caso individual del autor, quien pone en boca de su padre las intenciones relacionadas con el premio por su servicio, ${ }^{45}$ sino también para el aprovechamiento de las pretensiones individuales y grupales de los demás súbditos herederos del Tahuantinsuyu.

Aunque el Consejo de Indias tuvo por presunción lo contrario, no todos los textos históricos de este período pueden recibir una interpretación exclusiva en clave de retribución por servicios más o menos identificables que fueron prestados al rey o al reino. De hecho, hubo quienes se elevaron por encima de las pretensiones precisas para servir con relatos de más altos vuelos. Tal fue el caso de la Historia General del Perú de fray Martín de Murúa, ${ }^{46}$ quien constituyó uno de los más conspicuos ejemplos en posicionar el pasado incaico en un análisis de coordenadas europeas. Aunque otros, como el propio Inca Garcilaso o Felipe Guaman Poma, también lo ejercitaron, sin embargo en el texto de Murúa se fueron asimilando de manera metódica las peculiaridades culturales de las formas políticas peruanas a sus correspondientes en las monarquías de principios del siglo XVII. Los Incas fueron presentados como reino, monarquía e imperio, porque «no se puede negar a los Ingas, haber sido en el gobierno político de este tan extendido reino sumamente avisados, y discretos, gobernando estos indios conforme pide su naturaleza y condición». ${ }^{47}$ Las páginas se

44 En este sentido, la construcción de archivos como lugares de memoria y potenciales armas políticas, entre otras razones, fue un recurso frecuente en el siglo XVII. Véase Bouza, 2001, 268 y 283-284.

45 «Y que demás del servicio de vuestra Magestad que resultará imprimirse la dicha historia, comenzandose a celebrar y hacer inmortal la memoria y nombre de los grandes señores antepasados nuestros agüelos como lo merecieron sus hazañas, deseando que todo esto se consiga, humilmente suplico a vuestra Majestad sea servido de favorecer y hacer merced al dicho mi hijo don Felipe de Ayala y para todos mis nietos, para que su pretensión vaya adelante, que es lo que pretendo de que vuestra Magestad nuestro señor guarde y prospere por muchos y muy felices años con acrecentamiento de mas reinos y señoríos». Guaman Poma, 1987 [1615], 5-6.

46 Murúa, 1986 [1611-1613].

47 Ibidem, 351 . 
sucedieron en detalles que bien pudieron constituir la administración de Felipe III a través del sistema polisinodial en un entorno cortesano, y lo que emergió de las palabras escritas fue algo más importante que el afán pedagógico del fraile mercedario. Como si se tratara de una sustancia nutricia, el texto otorgó consistencia política a una entidad de gobierno anterior para revalidar la condición de reino del conjunto del Perú. Y mediante la descripción minuciosa de la actividad administrativa del imperio Inca se puso de manifiesto la compatibilidad del trasvase de un modelo en el que el Inca representó un verdadero monarca: «El modo con que los gobernaba [el Inca] era que tenía en el Cuzco, junto a su persona, cuatro señores orejones de los más principales, y de más experiencia y entendimientos, sabios en la paz y en la guerra, los cuales eran como cuatro consejeros de Estado, de cuyas manos y prudencia pendía todo el Reino, así en las cosas de policía como de guerra». El texto no solo asimiló la idea de un soberano en su corte junto a sus más leales servidores ejerciendo el deber de consejo, sino que fue más allá y sostuvo que esos leales fueron de la misma calidad que los consejeros de Estado: «Estos orejones eran de su linaje del Ynga, y parientes muy cercanos, o hermanos, o tíos, y después dél eran las personas de más autoridad en la corte». Estos hombres principales también «despachaban y proveían los negocios» y a su vez cada uno de ellos fue cabeza de consejos territoriales, no por materias, sino que actuaron como presidentes de otros consejos donde «cada uno tenía a su cargo una de las cuatro provincias dichas, de Colla Suyo, Ante Suyo, Conti Suyo y Chinchay Suyo». Al igual que en un consejo real de tipo territorial, «los que venían a negociar al Cuzco, acudían al suyo, el cual les oía, si eran negocios livianos, los proveían y despachaban ellos luego, sin detenerlos», lo que habría constituido una verdadera consulta a boca. Pero «si eran negocios de más calidad, los comunicaban entre sí, y si eran cosas arduas de mucho peso, daban cuenta al Ynga, y entraban en acuerdo, todos juntos con él, y si el que venía a negociar era curaca, o capitán, o indio principal, entraba él también en la consulta, para oírle el Ynga y que diese sus razones. Oídas, si el negocio pedía más acuerdo, llamaba a otros consejeros inferiores, con los cuales se confería y trataba, y con brevedad los despachaban».48 Los asuntos de los vasallos fueron sometidos a un proceso consultivo colegiado y a boca, llevado adelante por consejeros reales, sobre el que finalmente recayó la decisión del soberano. Al igual

48 Ibidem, 352 (las cursivas son mías). 
que esta cita, se podrían seguir enumerando diferentes ejemplos en este texto, y en otros, acerca de la asimilación entre el pasado político peruano y la monarquía hispánica, con una importante carga de revalidación política de la categoría del ámbito americano. Porque el asunto no fue baladí.

La condición que poseyeron los dominios americanos con anterioridad a ser incorporados tuvo profundas repercusiones. Una de ellas entronca directamente con la siempre debatida cuestión del modo de incorporación de América, dado que la naturaleza del gobierno que fue subsumido vino a completar las distintas interpretaciones respecto de si se trató, en definitiva, de una unión principal o accesoria de los reinos de Indias a la Corona de Castilla. ${ }^{49}$ Aunque el hecho de la conquista por la fuerza o la renuncia voluntaria del antiguo titular, pueda ser visto como un simple acto jurídico, lo cierto es que cada forma generó un tipo de relación con consecuencias políticas, y los acalorados debates que acompañaron el tema dan buena cuenta de su trascendencia funcional. En este sentido, la representación de una historia indiana en la que la condición gubernamental anterior a la llegada de los españoles fue una monarquía a semejanza de la hispánica, otorgó sustancia a la defensa de la consideración para los territorios indianos de reinos principales. De esta manera, los textos históricos que apoyaron la existencia de monarquías indianas coadyuvaron a robustecer el principio político de que las Indias merecieron un vínculo directo al poder real y una relación de iguales respecto de otros reinos del conglomerado monárquico.

Del mismo modo que lo hizo Murúa para el Perú, en el caso novohispano fue fray Juan de Torquemada quien elevó el pasado mexica a la categoría política de monarquía. ${ }^{50}$ Resulta destacable cómo Monarquía Indiana defendió el poder restaurador de la historia. El relato cierto de los hechos ocurridos, por sus características de texto contrastado, se entendió capaz de arrojar luz sobre las situaciones presentes y, de este modo, mostrarse como causa para la actuación de la justicia. El alegato de Torquemada acerca de una historia entendida como un «beneficio inmortal que se comunica a muchos» alude a sus propiedades inmutables, porque «los montes no la estrechan, ni los ríos, ni los años, ni los meses, porque ni está sujeta a la diferencia de los tiempos, ni del lugar». Desdeñando otros textos contemporáneos que, según esta tesitura, utilizaron el ejercicio de historiar para ensalzar hechos relacionados con la satisfacción de motivaciones egoístas,

49 Para la cuestión de la integración a la monarquía, véase Gil Pujol, 2012.

50 Torquemada, 1975 [1615]. 
se sostuvo que la verdadera historia, por sí sola, «es un enemigo grande y declarado contra la injuria de los tiempos, de los cuales claramente triunfa». Por ello, y en armonía con los nuevos modos historiográficos, se declaró la magnitud del compromiso que adquiría un auténtico historiador

porque escribir historia de verdades, no es tan fácil como algunos piensan; es menester, fuera de otras mil cosas, una diligencia grande en la inquisición de las cosas verdaderas, una madureza no menor en conferir las dudosas y en computar los tiempos, una prudencia particular y señalada en tratar las unas y las otras, y sobre todo, en la era en que estamos, es menester un ánimo santo y desembarazado para pretender agradar solo a Dios, sin aguardar de los hombres el premio. ${ }^{51}$

De ese modo, se justificó que las historias de las monarquías indianas no fueron esfuerzos denodados por encumbrar la antigüedad prehispánica, sino textos desinteresados sobre objetivas circunstancias pasadas. Ahora bien, en tanto y en cuanto estos tuvieron la capacidad de incoar la justicia, cabe subrayar que los textos históricos hicieron las veces de alambicadas defensas de la condición de aeque principaliter de los reinos de Indias, dejando al descubierto el implícito derecho político de los americanos a ser considerados vasallos de primera categoría y la obligación gubernativa de la Corona de estimar los asuntos indianos como esenciales por su naturaleza principal, en oposición a accesorios, en este caso, y principalmente, de Castilla.

Resulta revelador el hecho de que estas dos representaciones - de Murúa y Torquemada - sobre las monarquías indianas solventaron el obstáculo de la censura a través del dictamen favorable del cronista de Indias Pedro de Valencia. ${ }^{52}$ Es decir, aun cuando la última palabra la tuvo el Consejo de Castilla, el sínodo indiano avaló la erudita construcción de los antepasados históricos de los reinos indianos como entidades monárquicas que nada tuvieron que envidiar a otras. Allí se aseveró que tanto aztecas como incas practicaron estrategias imperiales de gobierno en territorios controlados jerárquicamente, comunicados y tributarios, con monarcas que encarnaron la justicia pero descansaron sus obligaciones en validos y consejos constituidos por orejones o pipiltin, se hicieron representar a la distancia en auquis o familiares que hicieron las veces de virreyes y respetaron las jurisdicciones de los nobles en sus señoríos, edificaron las admirables capitales del Cuzco y Tenochtitlán, donde se relacionaron al estilo cortesano,

51 Ibidem, XXVIII.

52 Ibidem, XXXIV. Murúa, 1986 [1611-1613], 42. 
y defendieron con ordenados ejércitos las causas del reino; y todo ello teniendo como guía los principios que, a pesar del desconocimiento del dios verdadero, consideraron como legítimos. Los relatos de las monarquías indianas llegaron a tal intensidad que Murúa se animó a concluir, a propósito del gran Tupa Inga Yupanqui, que «puso toda la tierra de su señorío en concierto y orden con tanta prudencia, que si hubiera leído las Políticas de Aristóteles y todo lo que la filosofía moral enseña, no pudieran haberse aventajado tanto». ${ }^{53}$

Aun con todos los matices que se pueden señalar entre ellos, y respecto de otros, la contribución de dichos textos a elevar la categoría de las Indias, con sus detalles minuciosos acerca de las estructuras gubernativas prehispánicas (y posteriores) al modo de la administración de cualquier reino europeo y dentro de la más florida etiqueta borgoñona, fue favorecida por un Consejo de Indias que siempre se mostró reticente a las cuestiones históricas, por lo que se ha señalado de su potencial calidad probatoria para las demandas de los vasallos. Sin embargo, fue proclive a las monarquías indianas. Estos textos obtuvieron la aprobación de mano de Pedro de Valencia: «porque la historia es muy útil y gustosa, por los ejemplos de prudencia y extrañeza y variedad de los sucesos, y está tratada con claridad y apacible estilo, y principalmente con celo de verdad y desapasionada intención». ${ }^{54}$

Ahora bien, ¿por qué se permitió que estas representaciones de América dieran el paso del manuscrito a la imprenta? Si bien esto puede explicarse en relación a los nuevos tiempos de la cultura escrita dentro de un contexto que ve nacer con fuerza los inicios de la opinión pública, ${ }^{55}$ debe señalarse que los argumentos que contribuyeron a considerar la condición de principal de los reinos de Indias fueron de incumbencia directa del sínodo americano, y que este apoyó los ejercicios históricos siendo muy consciente de sus consecuencias políticas. Más allá de la pertinencia administrativa o jurídica, y si se quiere teórico-política, en tanto y en cuanto los asideros históricos fueron parte trascendental en los cimientos de las construcciones discursivas, interesa subrayar que el Consejo de Indias instrumentalizó la historia de las monarquías indianas (y los primeros tiempos de la española en América) para reforzar la lucha por la condición principal de sus reinos pero también sus posicionamientos como consejo territorial en permanente

53 Murúa, 1986 [1611-1613], 99.

54 Garcilaso de la Vega, 1616, 1v.

55 Véase Olivari, 2014. 
batalla política por hacerse un lugar de mayor reconocimiento en el cuerpo de las instituciones reales. Porque, en definitiva, no fue lo mismo pertenecer al consejo que gestionaba unas monarquías de ricos reinos preexistentes, exóticos pero en esencia asimilables, que fueron trasladados al rey de manera voluntaria por parte de sus titulares e incorporados al cuerpo medular de la monarquía, que tenerse por integrante de un consejo representante de unos territorios anárquicos, conquistados y fagocitados por Castilla, cuyo mayor valor pudo traducirse en aportaciones monetarias.

Estas consideraciones no pueden pasar por meramente retóricas, ya que tuvieron consecuencias tangibles para los miembros del Consejo de Indias. La sumisión política que el poder real del Consejo de Castilla le impuso desde sus orígenes se tradujo en un yugo que condicionó las relaciones internas y externas del sínodo. Debe señalarse que para ser consejero indiano el nombramiento se alcanzó solo a través de la Cámara de Castilla, y no del propio consejo territorial, como en otros de la monarquía. De manera contraria a lo que sucedió en otros, que esta gracia recayera en un letrado con experiencia en los reinos representados constituyó una situación verdaderamente excepcional, por no hablar de la casi total exclusión de los americanos en la carrera por un asiento en $s u$ propio consejo. ${ }^{56}$ En este contexto, cobra sentido la interpretación que aquí se propone acerca de que el apoyo del Consejo de Indias a los escritos históricos que enaltecieron la condición principal americana debe también enmarcarse en la lucha política del sínodo americano por soliviantar la pesada opresión ejercida por el Consejo de Castilla y mejorar el espacio que ocupó en el entramado de las instituciones reales de consejo. Se trató, por lo tanto, de la dimensión fáctica de su poder en relación a los demás miembros del cuerpo real, ante los cuales fue patente la debilidad de un consejo sujetado por las fuerzas regnícolas del monarca y el valido, y de lo que estas tuvieron de representación en el Consejo de Castilla. Sin embargo, en los inicios del siglo XVII el Consejo de Indias no fue un observador impasible de sus desventuras, sino un activo sujeto político que se volcó a la disputa por alcanzar preeminencia auténtica como órgano supremo de sus reinos. En este sentido, las representaciones textuales de lo que sucedió con anterioridad a la llegada de los españoles a Indias y la forma en la que estos se hicieron con el poder en América, hicieron las veces de componentes de un arsenal de argumentos teóricos que buscaron efectividad política.

56 Véase Ponce Leiva, 2017. 


\section{La Hispania del Nuevo Mundo}

Dentro del corpus heterogéneo que historió las Indias se encuentran planteamientos que merecen ser señalados por su complejidad, originalidad, y por las distintas re-elaboraciones a las que fueron sometidos una y otra vez. Una cuestión neurálgica que recorrió estos textos versó sobre la riqueza indiana, su verdadera naturaleza y efectos. Mostrada como una problemática en sí misma, los discursos de contenido indiano histórico también reflexionaron y se pronunciaron sobre el tema. De hecho, y con la autoridad que otorgó la historia, estos textos resultaron claves por sus ejercicios de comparación con el pasado. La equiparación de las experiencias históricas ofreció respuestas para comprender la verdadera condición de los tesoros americanos, a la par que alimentó el debate político al que la cuestión estuvo sumamente ligada.

Al calor de una historia analítica para las Indias, el padre Acosta formuló una de las representaciones más sugerentes de su tiempo cuando sostuvo que América fue para la Monarquía Hispánica, lo que Hispania para el Imperio Romano. De este modo, el autor invocó «todo un mundo de estructuras de referencias que arrojan luz sobre el resto de sus palabras», ${ }^{57} \mathrm{y}$ franqueó el paso a nuevas interpretaciones sobre el pasado y presente indianos expresadas en el lenguaje común y legitimador de la tradición. ${ }^{58}$ En este sentido, las Indias también fueron objeto de los ejercicios de superposición con los relatos de los imperios antiguos, especialmente griegos y romanos, y con los avatares del pueblo escogido por Dios en cada momento de la historia.$^{59}$ El jesuita recurrió a los escritos de la Historia Natural de Plinio y al primer libro de los Macabeos para enunciar que las tierras de Hispania fueron «las mayores grandezas de los romanos, que hubieron a su poder los metales de plata y oro que hay en España». Del mismo modo, «agora a España le viene este gran tesoro de Indias». No por causa del azar o el arrojo de reyes o conquistadores, sino por voluntad de Dios, «ordenando la Divina Providencia que unos reinos sirvan a otros y comuniquen su riqueza, y participen de su gobierno para bien de los unos y los otros». De este modo, en el trasvase providencial de los papeles históricos, defendió que la

57 Pocock, 2011, 51.

58 Respecto de los recursos clásicos en los textos indianos véase el trabajo de Lupher, 2006. También Haase y Reinhold, 1994; Hampe, 1999; Osorio, 1991.

59 En estas coordenadas, es emblemática la obra Política Española de fray Juan de Salazar escrita durante el reinado de Felipe III y ejemplo de discurso sobre la intervención de Dios en la historia. 
riqueza no fue un bien patrimonial de los titulares, sino un acervo llamado al servicio de unos reinos a otros. Esto es, la riqueza que la divina providencia ofreció a los elegidos no se habría entregado para estar a merced de los deseos de los imperios. Muy al contrario, ese caudal se encontraría restringido a los fines para los cuales fue otorgado, subrayando Acosta que la voluntad divina solo encontraría cumplimiento «si usan debidamente de los bienes que tienen». ${ }^{60}$

Estas interpretaciones recorrieron varios de los textos gestados durante el reinado de Felipe III mencionados en este trabajo. Entre todos, interesa señalar el Memorial de las Historias del Nuevo Mundo, de fray Buenaventura de Salinas, por sus características de síntesis, crítica y erudición. ${ }^{61}$ Las motivaciones de la empresa textual fueron principalmente dos, a saber, «la suma de las Historias», ${ }^{62}$ es decir, la importante cantidad de historias de las Indias producidas en los inicios del siglo XVII (lo cual explicaría la necesidad de un ejercicio historiográfico esclarecedor), y el estado de los reinos, esto es, el infortunio americano como acicate para la escritura. Definida por el propio autor como un «retrato que saca deste mundo», ${ }^{63}$ en lo que aquí interesa y desde los presupuestos de unas Indias comparables a la Antigüedad, reconvertidas en la nueva Hispania e incorporadas a una monarquía vista como el imperio de su tiempo por la gracia de Dios, el texto construyó un fecundo edificio intelectual con marcado acento en las significaciones últimas de estas representaciones. Donde los paralelismos con el mundo clásico se desplegaron para entrar en comparación con la actividad y las ideas políticas de la Corona para las Indias, y especialmente para el Perú.

Salinas recuperó el hilo argumental acerca de que los antiguos se beneficiaron de las riquezas de Hispania del mismo modo que España lo hacía de Indias. Acosta había parafraseado algunos pasajes sobre Hispania de la Historia Natural, de Plinio el Viejo, para subrayar la actitud de explotación de la antigua Roma, porque aun cuando en Italia hubo metales «los antiguos no consintieron beneficiarse por conservar la gente. De España los traían, y como a tributarios, hacían a los españoles labrar minas». A partir de este hecho, Acosta extendió la misma lógica para su tiempo, «lo propio hace agora España con Indias, que habiendo todavía en España sin duda mucha riqueza de metales, no se dan a buscarlos ni aun se consiente labrar por los

60 Acosta, 2002 [1590], 271.

61 Cfr. Gálvez, 2008.

62 Salinas, 1957 [1631], 1.

63 Ibidem, 2. 
inconvenientes que se ven; y de Indias traen tanta riqueza, donde el buscarla y sacarla no cuesta poco trabajo, ni aun es poco riesgo». ${ }^{64}$ Con el refuerzo de esta comparación, introduciendo más citas de autores clásicos ${ }^{65}$ fray Buenaventura se mostró con mayor contundencia al sostener que la imitación de esta conducta igualó en ansias de riquezas, y en menosprecio de los naturales, a las dos potencias políticas.

Sin embargo, Salinas dio un giro más al carácter crítico del texto de Acosta, y de otros, para pasar a dejar mayor constancia de cómo fueron vulnerados estos fundamentos. A partir de una proclama que el autor dirigió al cerro del Potosí, como arquetipo de las Indias — por ser sinónimo de la riqueza indiana, el núcleo vital de los metales-, se subrayaron los fines a los que sirvió la abundancia americana. Los primeros en ser destacados fueron aquellos objetivos a los que estuvo llamada esa riqueza, y declaró al cerro que «vives dulcemente para Felipo IV, para sus Sucesores, para sus Reynos, para la Religión y la Justicia», también «vive para rebenque del Turco, para envidia del Moro, para temblor de Flandes, y terror de Inglaterra: vive, vive, columna y obelisco de la Fe». Y junto a estas afirmaciones halagadoras, introdujo términos polisémicos para destacar las desviaciones, las faltas de cumplimiento de los principios que debieron regir la utilización de las riquezas y declamó que el cerro también «vive para cumplir tan peregrinos deseos, como tiene España», dejando al buen entendedor elegir la acepción de «peregrinos», ya sea como extraño, raro, vano, o bien como adorno de singular hermosura, perfección o excelencia. Y aun hubo más, el Potosí fue presentado como el cerro de las muchas formas de vida, ya sea de naturaleza humana, animal, vegetal o divina. Así apareció en el texto como el humano a quien «templan las nieves su coraje, a quien coronan perpetuamente las nubes como al Rey de los cerros y las minas», o el «pelícano insensible, que porfiando por satisfacer la sed y codicia de los hombres, consientes que te abran las venas, que te rompan las entrañas, que te quebranten y carcoman tantos Indios, gusanos racionales, con dientes de acero, y almadenas de hierro», también el «árbol de plata vegetable, que mientras mas te podan, te arrojas mas ufano a los renuevos», y el semidiós heleno al que declara: «vive, pues, y persevera estable, con el favor de Dios, que te crió, para gloria de la ley mejor, que guardan cerros de minas: Hércules valiente». ${ }^{66}$

64 Acosta, 2002 [1590], 226.

65 Por ejemplo, cita como autoridades a Estrabón, Tito Livio, Trogo Pompeo, Latino Pacato y Plinio. Salinas, 1957 [1631], 241-243.

66 Ibidem, 250. 
De todas las citadas, la comparación con Hércules puede ser entendida como una de las más provocativas. Porque si el Potosí fue un Hércules, y enlazamos esta figuración con el carácter peregrino que el texto alude a los deseos de España, se pueden entender las riquezas del cerro como los trabajos del héroe en manos del monarca español, que pasaría entonces a ser Euristeo, el rey imperfecto. Resulta llamativa la osadía de dejar abierta la posibilidad a esta interpretación respecto del papel del rey, como aquel soberano que tiene en sus manos la voluntad del poderoso Hércules-Potosí, un Potosí que a su vez simboliza las Indias en su conjunto. El paralelismo elegido por el jesuita resulta revelador. Si se sigue el relato mitológico más consensuado, Euristeo fue un personaje atrapado en sus afanes, incapaz de reconocer la valía de Hércules y de sus esforzados a la par que mortíferos trabajos, un rey imposibilitado de dar a su vasallo el papel que sus méritos le hubiesen asignado. Al igual que Hércules, Potosí (o Indias) sufrió la orden de dejar los frutos de sus esfuerzos en la puerta del reino, más allá del coste de las tareas, y del mismo modo que sucedió al semidiós, le estuvo negada la entrada a participar en los beneficios reales. Pocas dudas quedan acerca de la dureza de la comparación. Ahora bien, posiblemente para mitigar sus efectos - y dejando al descubierto los eruditos mecanismos de la obra-, la que se acaba de enunciar no fue la única posible lectura de la relación entre Hércules y Euristeo, al igual que entre Potosí, o Indias, y su rey. Porque otra tradición, de época alejandrina, recogió un relato en el que se sostuvo que Hércules fue amante de Euristeo y que, en realidad, realizó cada uno de sus trabajos movido por el amor. ${ }^{67}$

\section{Conclusiones}

En el reinado de Felipe III el ámbito de representaciones textuales indianas conoció una renovación en las ideas y análisis teóricos que alimentaron las discusiones y las prácticas políticas de implicaciones americanas. En este sentido, la constatación de que hubo comunicación entre los escritos y los escritores, crítica y contra-crítica, en un entorno de continuidad, nos lleva a afirmar la consolidación de una comunidad política indiana en los inicios del siglo XVII. ${ }^{68}$ La verbalización de las problemáticas americanas

67 Para el relato de los trabajos de Hércules y su relación con Euristeo véase, por ejemplo, Apolodoro, 1982, 100-119. También Grimal, 2008, 186-187.

68 Pocock, 2011, 54. 
posibilitó la construcción y circulación de discursos y prácticas dentro de esta comunidad reciente y vigorosa, donde el poder de las representaciones constituyó una fuerza política compartida y en expansión. Si se tiene en cuenta el devenir de América a partir de su incorporación a la Corona de Castilla como una nueva sociedad fruto de esa unión, puede decirse que este fue el tiempo en que la sociedad indiana comenzó a desarrollar un corpus propio de teoría política y una forma particular de interpretar su historia. ${ }^{69}$ La madurez de las Indias avanzó hacia la determinación teórica de su propio ethos y tomó la decisión de dirigir y hacer realidad su pensamiento político.

La historia tuvo un importante papel en esta tarea. Especialmente porque América tuvo que utilizar todos los mecanismos a su alcance para hacerse un mejor lugar en el cuerpo de la monarquía hispánica. Aunque las sociedades occidentales fueron más proclives a expresar su pensamiento político en un lenguaje jurídico, no por ello se renunció al poder de la historia. Tal como sostuvo Acosta, hubo una razón muy particular por la que fue necesario hacer buenas historias de los reinos de Indias, y ello se debió al escaso aprecio que se tuvo a estos reinos y sus costumbres, parecer que le fue conferido a sus relatos «por ser de gentes poco estimadas». ${ }^{70}$ Razón de más para volcarse a la edificación y divulgación de textos analíticos del pasado americano, porque «quitan mucho del común y necio desprecio en que los de Europa los tienen [...] El desengaño de esta su vulgar opinión, en ninguna parte le pueden mejor hallar que en la verdadera narración de los hechos de esta gente». ${ }^{71}$

Coincidiendo con el interés por la disciplina dentro del auge de las teorías de la razón de Estado, los textos que surgieron respondieron también a otras motivaciones que pueden ser vistas en diferentes escalas. Por un lado, se ha visto cómo las pretensiones de justicia conmutativa y distributiva, ya sean individuales o colectivas, fueron encausadas hábilmente por los indianos a través del servicio de representar su pasado y presente en textos con alto contenido histórico. Por el otro, en los niveles de un discurso global dirigido a tener resonancias mayores, se elaboraron textos que erigieron la categoría de monarquías para el pasado prehispánico y asimilaron detalladamente los sistemas anteriores de gobierno y representación a la actualidad política hispánica, con la intención de asegurar el trasvase de la principalidad americana al corazón de la monarquía. Lejos de constituir una

69 Ibidem, 29.

70 Acosta, 2002 [1590], 419.

71 Ibidem, 420. 
serie de discursos doctos pero estériles, lo que sucedió con anterioridad a la llegada de los españoles a Indias y la forma en la que estos se hicieron con el poder, tuvo consecuencias políticas tangibles. Más allá de que una glorificación del pasado indiano fue permitida y avalada por el rey y el Consejo de Castilla, porque encumbró al conjunto de la monarquía y apuntaló su titularidad sobre los reinos, aquí interesa señalar que en el horizonte político americano, encabezado en la corte por el Consejo de Indias, las representaciones textuales históricas se tradujeron en demostrados argumentos con los que impugnar, en su labor de gobierno y justicia, el menosprecio para con sus reinos representados y, a la vez, ir socavando su incómoda calidad subordinada respecto de otros consejos de la monarquía, especialmente, del Consejo de Castilla. En este sentido, se puede decir que estos textos que representaron las Indias lograron hacerse presentes en el debate político de la monarquía, porque estimularon la incorporación de la calidad imperial del pasado prehispánico al igual que señalaron el camino para realizar múltiples posibles inferencias entre la historia indiana y la cultura clásica.

Cuando en las representaciones indianas se apeló a la Antigüiedad, y especialmente a Roma, no fue solo para utilizar un recurso común a la cultura política de la monarquía que permitió la comunicación y demostró la erudición del ámbito indiano, sino que también constituyó parte de los materiales con los que se elaboraron los cimientos del pensamiento político americano. Estos permitieron la sólida edificación de discursos anclados en las máximas autoridades consensuadas por la tradición europea, los cuales posibilitaron una lectura universal no solo del pasado y presente, sino también del futuro de América.

Recibido el 22 de septiembre de 2016 Segunda versión el 7 de febrero de 2017 Aceptado el 2 de marzo de 2017

\section{Referencias bibliográficas}

Acosta, José de, Historia Natural y Moral de las Indias, Madrid, Dastin, 2002 [1590].

Apolodoro, Biblioteca, Madrid, Gredos, 1985.

Bouza, Fernando, Corre Manuscrito. Una historia cultural del Siglo de Oro, Madrid, Marcial Pons, 2001.

Bouza, Fernando, Papeles y opinión. Políticas de publicación en el Siglo de Oro, Madrid, CSIC, 2008. 
Cárceles de Gea, Beatriz, «Las Indias y el concepto de riqueza en España en el siglo XVII», en Martínez Shaw, C. y Oliva Melgar, J. M. (eds.), El sistema atlántico español (siglos XVII-XIX), Madrid, Marcial Pons, 2005, 75-100.

Covarrubias Orozco, Sebastián, Tesoro de la Lengua Castellana, Madrid, Alicante, Biblioteca Virtual Miguel de Cervantes, 2006 [1611].

Cuesta Domingo, Mariano, «Los cronistas oficiales de Indias. De López de Velasco a Céspedes del Castillo», Revista Complutense de Historia de América, 33, Madrid, 2007, 115-150.

Chartier, Roger, El mundo como representación, Barcelona, Gedisa, 1992.

Chartier, Roger, La historia o la lectura del tiempo, Barcelona, Gedisa, 2007.

De los Reyes Gómez, Fermín, El libro en España y América. Legislación y Censura (siglos XV-XVIII), Madrid, Arco Libros, 2000.

Elliott, John, El Viejo Mundo y el Nuevo, 1492-1659, Madrid, Alianza, 1972.

Enciso Alonso-Muñumer, Isabel, «La etiqueta como lenguaje político. El conde de Lemos en el Consejo de Indias y en la corte virreinal de Nápoles», en Cantú, F. (ed.), Las cortes virreinales de la Monarquía española: América e Italia, Roma, Viella, 2008, 247-291.

Esteban Estríngana, Alicia (ed.), Servir al rey en la Monarquía de los Austrias. Medios, fines y logros del servicio al soberano en los siglos XVI y XVII, Madrid, Sílex, 2012.

Friede, Juan, «La censura española del siglo XVI y los libros de historia de América» en Revista de Historia de América, 47, Mexico, 1959, 45-95.

Gálvez Peña, Carlos M., «Prólogo» a Anello Oliva, Giovanni, Historia del Reino y Provincias del Perú [1630], Lima, Pontificia Universidad Católica del Perú, 1998, IX-LIII.

Gálvez Peña, Carlos M., «El carro de Ezequiel: la monarquía hispana de fray Buenaventura de Salinas y Córdova», Histórica, 32, 1, Lima, 2008, 39-75.

García Hernán, Enrique, «La España de los cronistas reales en los siglos XVI y XVII», Norba. Revista de Historia, 19, Badajoz, 2006, 125-150.

Garcilaso de la Vega, Inca, Comentarios Reales de los Incas, México, FCE, 1995 [1609].

Garcilaso de la Vega, Inca, Historia General del Perú, Córdoba, Viuda de Andrés de Barrera, 1616.

Gil Pujol, Xavier, «Introducción», en Leonardo de Argensola, Lupercio, Información de los sucesos del reino de Aragón en los años 1509 y 1591 [1604], Zaragoza, Astral, 1991, VII-XLVIII.

Gil Pujol, Xavier, «Integrar un mundo. Dinámicas de agregación y de cohesión en la Monarquía de España», en Mazín Gómez, O. y Ruiz Ibáñez, J. J. (eds.), Las Indias Occidentales. Procesos de incorporación territorial a las Monarquías Ibéricas (siglos XVI a XVIII), México, El Colegio de México, Red Columnaria, 2012, 69-108. 
González Ortega, Nelson, Relatos mágicos en cuestión. La cuestión de la palabra indígena, la escritura imperial y las narrativas totalizadores y disidentes en Hispanoamérica, Madrid, Iberoamericana-Vervuert, 2006.

Grimal, Pierre, Diccionario de mitología griega y romana, Barcelona, Paidós, 2008.

Guaman Poma de Ayala, Felipe, Nueva crónica y buen gobierno, Madrid, Historia 16, 1987 [1615].

Haase, Wolfgang y Reinhold, Meyer (eds.), The Classical Tradition and the Americas, Berlin, Walter de Gruyter, 1994.

Hampe Martínez, Teodoro (comp.), La tradición clásica en el Perú virreinal, Lima, Sociedad Peruana de Estudios Clásicos, Universidad Nacional Mayor de San Marcos, 1999.

Kagan, Richard L., Los Cronistas y la Corona. La Política de la Historia en España en las Edades Media y Moderna, Madrid, Marcial Pons, 2010.

Latasa Vasallo, Pilar (ed.), Discursos coloniales: texto y poder en la América hispana, Madrid, Frankfurt am Main, Iberoamericana, Vervuert, 2011.

Leonardo de Argensola, Bartolomé, Conquista de las islas Malucas, Madrid, Miraguano, Institución Fernando el Católico, Polifemo, 2009 [1609].

Lohmann Villena, Guillermo, «Estudio preliminar», en López de Caravantes, Francisco, Noticia General del Perú, BAE, Madrid, Atlas, 1985, IX-CXXIV.

Lupher, David A., Romans in a New World. Classical Models in Sixteenth-Century Spanish America, Ann Arbor, University of Michigan Press, 2006.

Morocho Gayo, Gaspar, «Introducción a una lectura de Pedro de Valencia. Primera Parte», en Valencia, P., Obras Completas. Vol.1: Relaciones de Indias. Nueva Granada y Virreinato de Perú, León, Universidad de León, 1993, 17-60.

Murúa, Martín de, Historia General del Perú, Madrid, Historia 16, 1986 [16111613].

Numhauser, Paulina, «Documentos Miccinelli; un estado de la cuestión», en Laurencich Minelli, Laura et al. (eds.), Per Bocca d'altri. Indios, gesuiti e spagnoli in due documenti segreti sul Perí del XVII secolo, Bologna, Universitá di Bologna, 2007, 45-74.

Olivari, Michel, Avisos, pasquines y rumores. Los comienzos de la opinión pública en la España del siglo XVII, Madrid, Cátedra, 2014.

Ortiz de Cervantes, Juan, Memorial que presenta a su Majestad el licenciado Juan Ortiz de Cervantes, Almería, Granata, 1968 [1619].

Ortiz de Cervantes, Juan, Información en favor del derecho que tienen los nacidos en las Indias a ser preferidos, Madrid, Viuda de Alonso Martín, 1620.

Osorio Romero, Ignacio et al., La Tradición clásica en Mexico, Mexico, UNAM, 1991.

Paniagua Pérez, Jesús, «Pedro de Valencia, cronista e historiógrafo oficial de las Indias (1607-1620)», Anuario de Estudios Americanos, Sevilla, 53-2, 1996, 231-249. 
Pizarro, Ana (ed.), América Latina: palavra, literatura e cultura, vol. I, Campinas, UNICAMP, 1993.

Pocock, John G. A., Pensamiento político e historia. Ensayos sobre teoría y método, Madrid, Akal, 2011.

Ponce Leiva, Pilar, «La argamasa que une los reinos: gestión e integración de las Indias en la Monarquía Hispánica, siglo XVII», Anuario de Estudios Americanos, 74-2, Sevilla, 2017, 461-490.

Saavedra Guzmán, Antonio de, El peregrino indiano, Madrid-Frankfurt, Iberoamericana-Vervuert, 2008 [1599].

Salinas y Córdova, Buenaventura de, Memorial de las Historias del Nuevo Mundo, Pirú, Lima, Universidad Nacional Mayor de San Marcos, 1957 [1631].

Torquemada, Juan de, Monarquía Indiana, Mexico, UNAM, Instituto de Investigaciones Científicas, 1975 [1615].

Valladares, Rafael, «Vasallos que se observan. Opinión y escritura imperial bajo la unión de coronas (1580-1640)», en Branco, Isabel Araújo et al. (eds.), Descrição geral do Reino do Peru, em particular de Lima, Lisboa, CHAM, 2013, 55-68.

Villarreal Brasca, Amorina, «La provisión de la presidencia del Consejo de Indias en el VII conde de Lemos: vínculos y méritos durante el valimiento del duque de Lerma», en Ponce Leiva, P. y Andújar Castillo, F. (eds.), Mérito, venalidad y corrupción en España y América, siglos XVII y XVIII, Valencia, Albatros, 2016, 57-74.

Zapata y Sandoval, Juan, De iustitia distributiva et acceptione personarum ei opposita disceptatio, Madrid, CSIC, 2004 [1609]. 